\title{
Predictive potential of the global bankruptcy models in the tourism industry
}

\author{
Potencial predictivo de los modelos globales de quiebras en la industria turística
}

\author{
Agustín del Castillo García \\ Finance and Accounting Department, University of Malaga, Malaga, Spain, adelcas@uma.es
}

Sergio Manuel Fernández Miguélez

MAINAKE Research Group, University of Malaga, Malaga, Spain, sergiofernandezmiguelez@uma.es

Received: 19.04.2021; Revisions required: 14.07.2021; Accepted: 15.10.2021

\begin{abstract}
The globalisation process and the recent economic crises have increased the development of models to identify the factors related to business bankruptcy. The tourism industry is not immune to this concern, and in the previous literature, bankruptcy prediction models are generally focused on hotels or restaurants. However, there are no experiences of global models for tourism companies. This study develops a global bankruptcy prediction model capable of predicting any activities carried out in the tourism industry with high precision. To this end, a sample of 406 Spanish companies that have developed their activity in three tourism industry sectors (hotels, restaurants, and travel agencies) in the period 2017-2019 has been used. This sample includes bankrupt and non-bankrupt corporations and has allowed the comparison between a global model and various focused models applying artificial neural network techniques. The results have confirmed the superiority of the global model and provide different sample selection and cost minimisation solutions for bankruptcy prediction modelling in the tourism industry.
\end{abstract}

Keywords: Bankruptcy, prediction, tourist firms, artificial neural networks, multi-layer perceptron.

\section{Resumen}

El proceso de globalización y las recientes crisis económicas han incrementado el desarrollo de modelos para identificar los factores relacionados con la quiebra empresarial. La industria turística no es ajena a esta preocupación y en la literatura anterior existen algunos modelos de predicción de quiebra, generalmente enfocados a hoteles o restaurantes. Sin embargo, no existen experiencias de modelos globales para empresas turísticas. Este estudio desarrolla un modelo global de predicción de quiebra capaz de predecir con alta precisión en cualquiera de las actividades que se llevan a cabo en la industria turística. Para ello, se ha utilizado una muestra de 406 empresas españolas que han desarrollado su actividad en tres sectores de la industria turística (hoteles, restaurantes y agencias de viajes) en el periodo 2017-2019. Esta muestra incluye corporaciones en quiebra y no quebradas, y ha permitido la comparación entre un modelo global y varios modelos focalizados aplicando técnicas de redes neuronales artificiales. Los resultados han confirmado la superioridad del modelo global y proporcionan diferentes soluciones de selección muestral y minimización de costos para el modelado de predicción de quiebra en la industria del turismo.

Palavras-chave: Quiebra, predicción, empresas turísticas, redes neuronales artificiales, perceptrón multicapas.

\section{Introduction}

Recent international economic crises have caused the bankruptcy of many companies, both at the country and industry level (Amankwah-Amoah, Khan \& Wood, 2021; Higashide, Kinkyo \& Hamori, 2019). Scientific literature has not been immune to this phenomenon, and studies on corporate bankruptcy have experienced substantial growth. Some of these studies have developed models to predict bankruptcy in specific industries, and others have been referred to different geographical areas.

However, few have focused on companies in the tourism industry (Becerra-Vicario et al., 2020). Tourism activity is closely related to economic growth, and in times of crisis, many tourism companies have also gone bankrupt. The previous literature that has developed models to predict the bankruptcy of tourism companies has focused mainly on hotels and restaurants, and its main conclusions point to a set of bankruptcy predictors specific to each type of tourism company (Kim \& Upneja, 2014; Gu, 2002).

On the other hand, and due to the globalisation process of the world economy, other studies have pointed out the need to create global models to predict bankruptcy. These models use the characteristics shared by companies in the same industry or region and offer numerous advantages related to optimising time, cost, and precision (Alaminos, del Castillo \& Fernández, 2016). Another aspect to which the global models respond is sample selection, offering the choice of the most convenient sample for the construction of bankruptcy prediction models. In this regard, there are already conclusions about the greater precision of global models in specific regions of the world (Korol, 2013) and specific industries (Laguillo et al., 2019). However, no experiences are available for the tourism industry. Solving the sample selection problem indicating whether a global model is superior to a model focused is important for the tourism industry because different activities, such as hotels, restaurants, and travels agencies, are carried out in it. This study covers this gap in the literature on tourism and develops a comparative analysis between models focused on the main tourism sectors and a global model for the entire tourism industry. For this, different models of a global nature and others focused on hotels, restaurants, and travel agencies have been designed, applying techniques of artificial neural networks (ANN). The results obtained indicate that the global model is superior to the centred models when it considers generic predictors and specific predictors of the different tourist 
activities. These results have important implications for minimising the design cost and increasing the accuracy of bankruptcy prediction models in the tourism industry.

\section{Literature review and research hypotheses}

The first studies on bankruptcy prediction by Altman (1968) and Ohlson (1980) gave way to later works that have been increasing the precision of the prediction models through different techniques (Atiya, 2001; Lin, 2009). The results obtained by them have reported precisions from $72 \%$ obtained by Altman (1968) with statistical techniques to $100 \%$ by Wu et al. (2007) with ANN.

In this context of growing attention to the bankruptcy factors, models with predictive capacity have been developed in the generality of possible business cases and situations, which have been called global models. The one prepared by Zhou (2013) with statistical and computational methods using a sample of North American and Japanese companies stands out. Also, that of Callejón et al. (2013) for the European manufacturing industry using Multilayer Perceptron (MLP). Their results indicate an accuracy of more than $92 \%$ with information from two years before the bankruptcy of the companies. For their part, Tsai, Hsu and Yen (2014), with a sample of Australian, German, and Japanese companies, achieved good precision results with a global model using ANN techniques. In the same sense, Korol (2013) built a global model with a sample of European and American companies. His conclusions confirm that ANN offers a high degree of predictive capacity. Alaminos, del Castillo and Fernández (2016) developed a global model with samples of Asian, European, and American companies and concluded that its precision was higher than that of the models focused on each region with information of up to three years before the bankruptcy. Recently, Laguillo et al. (2019) used a sample of Spanish companies from different industries and found that the global model built surpassed the models focused on each industry.

For the tourism industry, bankruptcy prediction models focused on hotel or restaurant samples, and only some of them have global samples that collect various tourist activities. Among the models focused on certain tourist activities, the one by Li and Sun (2012) for Chinese hotels stands out. Their results indicate the superiority of ANN over traditional statistical techniques using information from two years before the bankruptcy situation. Also, using an exclusive sample of Spanish hotels, Fernández Gámez, Cisneros-Ruiz and Callejón-Gil (2016) managed to improve the precision of existing models using the Probabilistic Neural Network. For their part, and with a sample of restaurants, Gu (2002) and Kim and Gu (2006a) built models for companies in the American market that provided an accuracy of over $80 \%$. Later, Young and Gu (2010) and Park and Hancer (2012) estimated models with statistical and computational techniques using a sample of American restaurants, and their results reached an accuracy close to $97 \%$. Recently, Becerra-Vicario et al. (2020) also used statistical and computational techniques in a model developed to predict the bankruptcy of Spanish restaurants. Specifically, the Deep Recurrent Convolutional Neural Network technique outperformed Logistic Regression (Logit) in precision. Finally, and with samples of travel agencies in the Czech Republic, the study by Hedija (2019) used the Z Score model and concluded that $30 \%$ of the companies in the sample were threatened by bankruptcy.

On the other hand, among the studies that have developed prediction models based on global samples of companies with different tourist activities, the one by Gu and Gao (2000) stands out, who developed a bankruptcy prediction model applying Multi-Discriminant Analysis (MDA) for a sample of American hotels and restaurants. Also, that of Kim and Gu (2006b), in which a model with Logit methodology was defined for a sample of hotels, restaurants, and casinos. Similarly, Park and Hancer (2012) study aimed to compare the precision of ANN and Logit in a sample of hotels, restaurants, and entertainment service companies. Their results showed the superiority of ANN in terms of predictive capacity. Finally, Pacheco (2015) used MDA and Logit models to determine which factors determine a greater probability of bankruptcy for Portuguese hotels and restaurants. The results show that the financial leverage variables are the best predictors, with an accuracy of $69 \%$.

The conclusions of the previous literature on bankruptcy prediction in the tourism industry have therefore indicated that models focused on hotel or restaurant activities could achieve adequate levels of precision (Park \& Hancer, 2012; BecerraVicario et al., 2020). Also that the ANN surpasses in precision the conventional statistical techniques (Li \& Sun, 2012; Fernández Gámez, Cisneros-Ruiz \& Callejón-Gil, 2016). On the other hand, it has been possible to verify that only some studies have developed global models combining samples of different tourist activities (Gu and Gao, 2000; Pacheco, 2015), but no study has addressed the comparison of global models versus models focused in the tourism industry. Knowing that the superiority of global models has reported significant advantages of costs and estimation precision in other industries (Alaminos, del Castillo and Fernández, 2016), we have formulated the following research hypotheses about the construction of global models of bankruptcy prediction in the tourism industry.

The first hypothesis is established concerning the use of generic variables and variables related to specific sectors of tourism activity. In this sense, we want to know the advantages of using generic and sectoral variables together in the models built with global samples, and it is specified in the following way:

Hypothesis 1 (H1): The use of sectoral variables improves the precision of the global bankruptcy prediction models developed for the tourism industry.

On the other hand, with the contrast of the second hypothesis, an attempt is made to explain the superiority of global models 
compared to those focused on a specific activity. Then, we postulate:

Hypothesis 2 ( $\mathrm{H} 2)$ : Global models with sectoral variables correctly predict bankruptcy for any tourism activity.

\section{Methods}

The present study uses ANN for the development of bankruptcy prediction models. Specifically, the so-called MLP is used, which has provided excellent predictive results in previous research related to bankruptcy in the tourism industry (Li \& Sun, 2012). Along with MLP, computational techniques have also been applied to know the sensitivity of the independent variables and the importance of their impact (Becerra-Vicario et al., 2020).

In ANN, the artificial neuron is the basic element of the system. It is made up of an input element and an output element that is processed in a central unit to perform training and generalisation functions (Jain, Mao \& Mohiuddin, 1996). For its part, MLP is a type of ANN formed by three layers of neurons (input, hidden, and output) that process information using an error correction algorithm. In this sense, the network evaluates its performance based on the deviations between the input and output values and modifies its parameters to minimise these differences. MLP represents a functional approach with the ability to solve non-linear problems and does not require a prior hypothesis about the relationship between the explanatory variables (Nuñez de Castro \& Von Zuben, 1998). During the training process, MLP uses the error function $E(W)$ that appears in (1), and from the learning patterns $\{(x 1, y 1),(x 2, y 2) \ldots$ (xp, $y p)\}$ try to find the weight of each variable $(W)$ that allows minimising the error.

$$
\min _{W} E(W)=\min _{W} \sum_{i=1}^{p} \varepsilon\left(W, x_{i}, y_{i}\right)
$$

A sensitivity analysis is used in a complementary way to the above, and to know the importance that each independent variable has to explain the problem under study. This analysis allows quantifying the impact of each variable in the solution proposed by MLP (He, Zhao \& Sun, 2019). For this, the sensitivity expression that appears in (2) is used.

$$
S x_{i}=\sum_{j=1}^{n}\left(\Phi x_{i j}(0)-\Phi x_{i j}\right)^{2}
$$

where $\Phi x_{i j}(0)$ is the value assigned to the output of the network when the variable $x_{i}$ is $0, \Phi x_{i j}$ is the known classification value, and $S x_{i}$ is the sensitivity result for each of the variables.

Together with the ANN, the present study uses different statistical criteria to evaluate the goodness of the developed models. Specifically, they are the model selection criteria proposed by Akaike (1973), Schwarz (1978) and Hannan and Quinn (1979). The criterion of Akaike (1973) is expressed according to (3) and is based on the maximisation of the plausibility function logarithm expected.

$$
A I C=2 k-2 \operatorname{Ln}(L)
$$

where $k$ is the number of parameters and $L$ is the maximum value of the plausibility function. For its part, the Schwarz (1978) criterion is an alternative criterion to the previous one and uses a Bayesian approach that penalises the number of parameters with $L n(n)$ instead of 2 . Its expression appears in (4).

$$
B I C=-2 \operatorname{Ln}(L)+\operatorname{Ln}(n)+k
$$

where $n$ represents the number of observations.

Finally, the criterion proposed by Hannan and Quinn (1979), which modifies the one proposed by Schwarz (1978), has a lower sample size penalty and is specified as it appears in (5).

$$
H Q C=-2 \operatorname{Ln}(L)+2 \operatorname{Ln}[\operatorname{Ln}(n)] k
$$

The three proposed criteria select the model that minimises the AIC, BIC, or HQC values.

\section{Sample and variables}

This study uses a sample of 406 Spanish tourism companies that carry out their activity in the hotel, restaurant, and travel agency segments. The companies' data in the sample correspond to the period 2017-2019 and were obtained from the Bureau van Dijk's Iberian Balance Systems database, which includes information on more than 1 million Spanish and Portuguese companies. Of the total number of companies in the sample, 203 are in a legal situation of bankruptcy, and the rest of the companies are in an active situation (not bankrupt). All were randomly selected through a stratified sampling according to the number of companies classified as hotels, restaurants, and travel agencies in the Spanish market. Thus, the global sample includes $33.99 \%$ from hotels, $52.71 \%$ from restaurants, and $13.30 \%$ from travel agencies (Table 1 ). From the global sample, three different subsamples have been established for each tourist activity analysed. Each of these subsamples includes bankrupt companies (with information corresponding to 2 years before the bankruptcy situation) and active companies (with paired information regarding the years of bankrupt companies) (Korol, 2013). Likewise, and to check the predictive capacity of the models, $80 \%$ of the data have been reserved for creating training samples and the remaining $20 \%$ for testing samples.

Table 1 - Sample distribution

\begin{tabular}{|c|c|c|c|c|}
\hline & NB & B & Total & $\%$ \\
\hline Hotels & 69 & 69 & 138 & 33.99 \\
\hline Restaurants & 107 & 107 & 214 & 52.71 \\
\hline Travel agencies & 27 & 27 & 54 & 13.30 \\
\hline Total & 203 & 203 & 406 & 100.00 \\
\hline
\end{tabular}

B: Bankruptcy firms; NB: Non-bankruptcy firms. 
For their part, the variables used in this research have been selected from previous studies of bankruptcy prediction in the tourism industry and include aspects related to liquidity, profitability, efficiency, and financial structure of the companies in the sample. Specifically, the variables for the construction of the global model come from the studies of $\mathrm{Gu}$ and Gao (2000), Kim and Gu (2006b), Park and Hancer (2012), and Pacheco (2015). Those corresponding to the hotel sector, from the studies by Li and Sun (2012) and Fernández Gámez et al. (2016). Those of restaurants, by Gu (2002), Kim and Gu (2006a), and Becerra-Vicario et al. (2020). Finally, those of travel agencies with those used by Hedija (2019). Table 2 presents a detail of independent variables. Along with the previous variables, a binary dependent variable has been considered that takes the value 1 if the company is bankrupt and 0 otherwise.

Table 2 - Independent variables

\begin{tabular}{|c|c|c|}
\hline Variable & Code & Description \\
\hline \multicolumn{3}{|l|}{ GLOBAL MODEL } \\
\hline Current Ratio & VG1 & Current Assets/Current Liabilities \\
\hline Efficiency Ratio & VG2 & Turnover Total Assets \\
\hline Return on Equity & VG3 & Net Profit/Net Equity \\
\hline Return on Assets & VG4 & EBIT/Total Assets \\
\hline Leverage & VG5 & Total Liabilities/Total Assets \\
\hline Liabilities Coverage & VG6 & EBITDA/Current Liabilities \\
\hline \multicolumn{3}{|l|}{ HOTEL MODEL } \\
\hline Free Cash-Flow & VH1 & Free Cash Flow/ Total Liabilities \\
\hline Net Profit Margin & $\mathrm{VH} 2$ & Net Profit/Turnover \\
\hline \multicolumn{3}{|l|}{ RESTAURANT MODEL } \\
\hline Gross Profit Margin & VR1 & Gross Profit/Turnover \\
\hline Long-Term Ratio & VR2 & Long-Term Liabilities/Total Assets \\
\hline \multicolumn{3}{|l|}{ TRAVEL AGENCY MODEL } \\
\hline Working Capital Ratio & VT1 & Working capital/Total Assets \\
\hline Retained Profit Ratio & VT2 & Retained profit/Total Assets \\
\hline
\end{tabular}

\section{Results}

\subsection{Descriptive analysis}

Table 3 shows the main descriptive statistics corresponding to the global sample. In general, the mean values of the variables are higher for non-bankrupt companies, except in the case of variable VG5, for which bankrupt companies present a higher mean value. It is also found that the variables present a moderate dispersion since the standard deviation values do not exceed the mean values.

Table 3 - Descriptive statistics (Total sample)

\begin{tabular}{|c|c|c|c|c|}
\hline Variables & \multicolumn{2}{|c|}{ Mean } & \multicolumn{2}{c|}{ S.D. } \\
\hline & $\mathrm{B}$ & $\mathrm{NB}$ & $\mathrm{B}$ & $\mathrm{NB}$ \\
\hline VG1 & 0.692 & 1.691 & 0.487 & 1.270 \\
\hline VG2 & 0.895 & 1.499 & 0.743 & 1.264 \\
\hline VG3 & -0.107 & 0.172 & 0.081 & 0.120 \\
\hline VG4 & -0.060 & 0.049 & 0.055 & 0.028 \\
\hline VG5 & 0.858 & 0.533 & 0.694 & 0.520 \\
\hline VG6 & 0.026 & 0.289 & 0.013 & 0.241 \\
\hline
\end{tabular}

B: Bankruptcy firms; NB: Non-bankruptcy firms.

On the other hand, Tables 4,5 , and 6 present the main descriptive statistics of the subsamples of hotels, restaurants, and travel agencies, respectively. The mean values of the variables corresponding to bankrupt companies are generally lower than those of non-bankrupt companies, except variable VG5. These results indicate that bankrupt companies have a higher level of leverage than non-bankrupt ones. Also that these present higher levels of liquidity, profitability, and efficiency than the former. Therefore, the selected variables may be appropriate to explain the bankruptcy of the companies in each subsample, although this point should be confirmed later with the MLP models developed.

Table 4 - Descriptive statistics (Hotels)

\begin{tabular}{|c|c|c|c|c|}
\hline & \multicolumn{2}{|c|}{ Mean } & \multicolumn{2}{c|}{ S.D. } \\
\hline & B & NB & B & 0.853 \\
\hline VG1 & 0.472 & 1.132 & 0.304 & 0.297 \\
\hline VG2 & 0.229 & 0.458 & 0.178 & 0.099 \\
\hline VG3 & -0.097 & 0.145 & 0.083 & 0.035 \\
\hline VG4 & -0.024 & 0.042 & 0.021 & \\
\hline
\end{tabular}




\begin{tabular}{|l|l|l|l|l|}
\hline & \multicolumn{2}{|c|}{ Mean } & \multicolumn{2}{c|}{ S.D. } \\
\hline VG5 & 0.871 & 0.402 & 0.519 & 0.201 \\
\hline VG6 & 0.028 & 0.127 & 0.019 & 0.084 \\
\hline VH1 & 0.002 & 0.086 & 0.001 & 0.001 \\
\hline VH2 & -0.016 & 0.028 & 0.011 & 0.007 \\
\hline
\end{tabular}

B: Bankruptcy firms; NB: Non-bankruptcy firms.

Table 5 - Descriptive statistics (Restaurants)

\begin{tabular}{|c|c|c|c|c|}
\hline & \multicolumn{2}{|c|}{ Mean } & \multicolumn{2}{c|}{ S.D. } \\
\hline Variables & B & NB & NB \\
\hline VG1 & 0.866 & 2.145 & 0.529 & 1.139 \\
\hline VG2 & 1.189 & 2.047 & 1.031 & 1.340 \\
\hline VG3 & -0.124 & 0.203 & 0.058 & 0.137 \\
\hline VG4 & -0.093 & 0.051 & 0.052 & 0.036 \\
\hline VG5 & 0.849 & 0.614 & 0.730 & 0.594 \\
\hline VG6 & 0.023 & 0.437 & 0.014 & 0.288 \\
\hline VR1 & -0.044 & 0.036 & 0.039 & 0.028 \\
\hline VR2 & 0.476 & 0.512 & 0.376 & 0.501 \\
\hline
\end{tabular}

B: Bankruptcy firms; NB: Non-bankruptcy firms.

Table 6 - Descriptive statistics (Travel Agencies)

\begin{tabular}{|c|c|c|c|c|}
\hline & \multicolumn{2}{|c|}{ Mean } & \multicolumn{2}{c|}{ S.D. } \\
\hline Variables & B & NB & B \\
\hline VG1 & 0.404 & 1.555 & 0.317 & 1.290 \\
\hline VG2 & 2.505 & 5.413 & 2.272 & 3.491 \\
\hline VG3 & -0.173 & 0.146 & 0.141 & 0.128 \\
\hline VG4 & -0.025 & 0.094 & 0.020 & 0.045 \\
\hline VG5 & 0.668 & 0.571 & 0.604 & 0.249 \\
\hline VG6 & 0.010 & 0.212 & 0.005 & 0.195 \\
\hline VT1 & -0.083 & 0.105 & 0.075 & 0.083 \\
\hline VT2 & 0.006 & 0.027 & 0.003 & 0.021 \\
\hline
\end{tabular}

\subsection{MLP models}

Table 7 presents the results obtained with MLP for the total sample data without using sectoral variables. The model's accuracy reaches $94.036 \%$ with the training data and $92.463 \%$ with the testing data. Furthermore, the area under the ROC curve is close to 1 (0.941), indicating that the model's goodness is correct. For its part, Figure 1 illustrates the sensitivity of the independent variables. The variables with the most significant impact are VG4, VG6, and VG2, so profitability, debt coverage, and efficiency are the best bankruptcy predictors.

Table 7- Global model results (without sectoral variables)

\begin{tabular}{|c|c|c|c|c|c|}
\hline \multicolumn{2}{|c|}{ Accuracy (\%) } & Goodness of fit & \multicolumn{3}{|c|}{ Model Selection Criteria } \\
\hline Training data & Testing data & ROC curve & AIC & BIC & HQC \\
\hline 94.036 & 92.463 & 0.941 & 153.920 & 167.981 & 150.558 \\
\hline
\end{tabular}

ROC: Receiver Operating Characteristic; AIC: Akaike criterion; BIC: Schwarz criterion; HQC: Hannan and Quinn criterion.

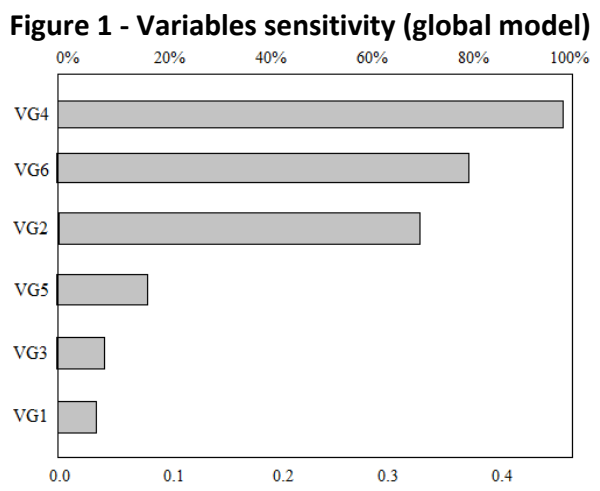

To test hypothesis $\mathrm{H} 1$, that is, to know if the use of sectoral variables improves the predictive capacity of global models for the tourism industry, a new model has been built that, together with the generic independent variables, uses variables specific to the tourism sectors. The results obtained appear in Table 8. The precision of this new global model amounts to $96.502 \%$ with the training data and $93.779 \%$ with the testing data. It also presents an excellent goodness of fit (ROC curve area $=0.962$ ) 
and assessment criteria (AIC, BIC, and $\mathrm{HQC}$ ) better than those obtained for the model without sectoral variables. Therefore, $\mathrm{H} 1$ is accepted and implies that the introduction of sectoral variables increases the predictive capacity of global models. The sensitivity of the variables considered in this model appears in Figure 2.

Table 8 - Global model results (with sectoral variables)

\begin{tabular}{|c|c|c|c|c|c|}
\hline \multicolumn{2}{|c|}{ Accuracy (\%) } & Goodness of fit & \multicolumn{3}{c|}{ Model Selection Criteria } \\
\hline Training data & Testing data & ROC curve & AIC & BIC & HQC \\
\hline 96.502 & 93.779 & 0.962 & 151.733 & 161.204 & 145.390 \\
\hline
\end{tabular}

ROC: Receiver Operating Characteristic; AIC: Akaike criterion; BIC: Schwarz criterion; HQC: Hannan and Quinn criterion.

Figure 2 - Variables sensitivity (global model with sectoral variables)

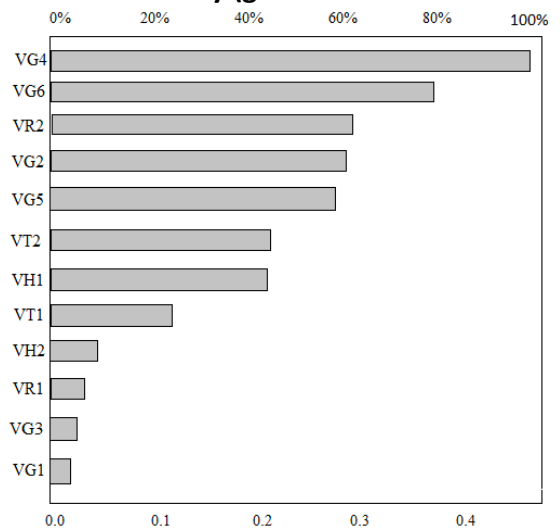

On the other hand, to test whether the global models with sectoral variables predict bankruptcy correctly for any tourist activity (hypothesis $\mathrm{H} 2$ ), three models have been built focused on each of the activities under study. Subsequently, the results of these focused models have been compared with those obtained by the global model using exclusive data from the sectoral samples (hotels, restaurants, and travel agencies). precision with the test data ranges between $89.729 \%$ for travel agencies and $90.989 \%$ for restaurants. Besides, all the models present an adequate goodness of fit, since in all cases the area under the ROC curve is close to 1 . On the other hand, the variables with the highest sensitivity are VG4, VG3, and VH2 (for hotels), VG5 and VR1 (for restaurants), and VG6 (for travel agencies), in all cases with an impact greater than $60 \%$.

Table 9 and Figure 3 present the results and the sensitivity of the variables of the focused models, respectively. Their

Table 9 - Focused models results

\begin{tabular}{|c|c|c|c|c|c|c|}
\hline & \multicolumn{2}{|c|}{ Accuracy (\%) } & Goodness of fit & \multicolumn{2}{c|}{ Model Selection Criteria } \\
\hline & Training data & Testing data & ROC curve & AIC & BIC & HQC \\
\hline Hotels & 91.733 & 90.215 & 0.938 & 279.317 & 293.844 & 263.201 \\
\hline Restaurants & 92.089 & 90.989 & 0.940 & 258.203 & 263.772 & 252.481 \\
\hline Travel Agencies & 90.101 & 89.729 & 0.921 & 290.286 & 298.815 & 288.304 \\
\hline
\end{tabular}

ROC: Receiver Operating Characteristic; AIC: Akaike criterion; BIC: Schwarz criterion; HQC: Hannan and Quinn criterion.

Figure 3 - Variables sensitivity (Focused models)

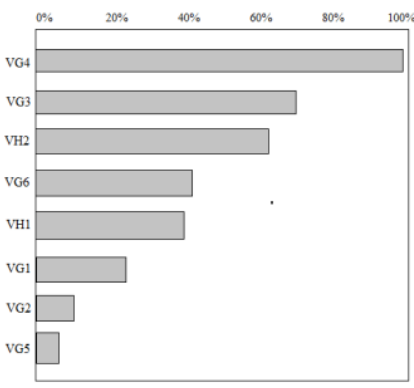

Hotels

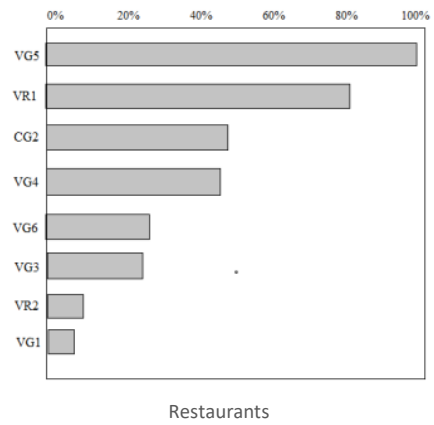

Restaurants

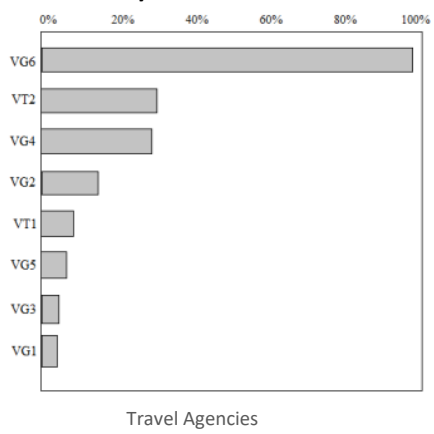


Likewise, Table 10 shows the results obtained by applying the global model with sectoral variables in each of the subsamples (hotels, restaurants, and travel agencies). The precision of the global model in all cases exceeds $88 \%$ with testing data, and the ROC curve also indicates a good fit. For its part, Figure 4 illustrates the sensitivity of the variables.

Table 10 - Global model with sectoral variables

\begin{tabular}{|c|c|c|c|c|c|c|}
\hline & \multicolumn{2}{|c|}{ Accuracy } & \multirow{2}{*}{$\begin{array}{c}\text { Goodness of fit } \\
\text { ROC curve }\end{array}$} & \multicolumn{3}{|c|}{ Model Selection Criteria } \\
\hline & Training data & Testing data & & AIC & $\mathrm{BIC}$ & $\mathrm{HQC}$ \\
\hline Hotel sample & 92.733 & 90.636 & 0.953 & 172.572 & 181.461 & 170.885 \\
\hline Restaurant sample & 93.402 & 91.320 & 0.957 & 165.290 & 178.536 & 161.072 \\
\hline Travel agency sample & 90.731 & 88.437 & 0.948 & 174.337 & 190.914 & 173.280 \\
\hline
\end{tabular}

ROC: Receiver Operating Characteristic; AIC: Akaike criterion; BIC: Schwarz criterion; HQC: Hannan and Quinn criterion.

Figure 4 - Variables sensitivity (global model with sectorial predictors in sectorial samples)

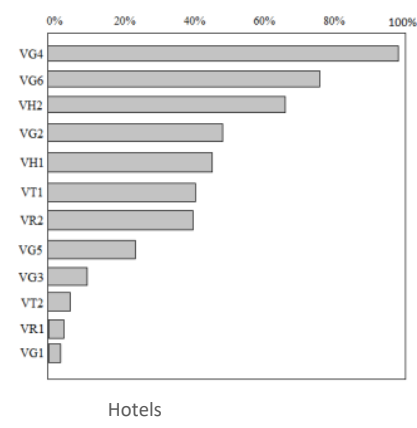

Hotels

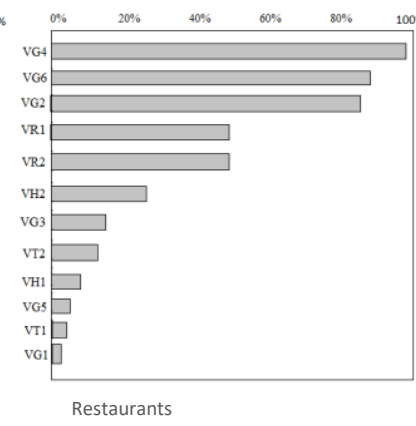

Restaurants

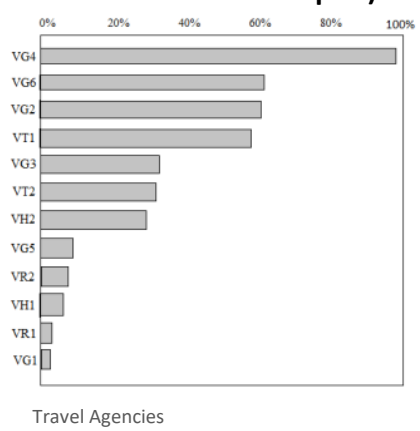

Finally, a comparison of the goodness of the models built to test hypothesis $\mathrm{H} 2$ appears in Table 11. The selection criteria of the models used (AIC, BIC, and HQC) indicate that the global model predicts with greater precision than the models focused on each sectorial sub-samples (hotels, restaurants, and travel agencies). In this regard, the values obtained by the global

model in the AIC, BIC, and HQC criteria are consistently lower than those corresponding to the focused models, so this $\mathrm{H} 2$ must be accepted. Consequently, it is verified that a global model with sectoral variables can predict better than models focused on any of the tourist activities.

Table 11 - Global model vs focused models

\begin{tabular}{|l|c|c|c|}
\hline & AIC & BIC & HQC \\
\hline HOTELS & & & \\
\hline Focused model & 279.317 & 293.844 & 263.201 \\
\hline Global model & 172.572 & 181.461 & 170.885 \\
\hline RESTAURANTS & & & \\
\hline Focused model & 258.203 & 263.772 & 252.481 \\
\hline Global model & 165.290 & 178.536 & 161.072 \\
\hline TRAVEL AGENCIES & & & \\
\hline Focused model & 290.286 & 298.815 & 288.304 \\
\hline Global model & 174.337 & 190.914 & 173.280 \\
\hline
\end{tabular}

AIC: Akaike criterion; BIC: Schwarz criterion; HQC: Hannan and Quinn criterion.

\subsection{Discussion}

The models developed in the present study indicate that ANN offers a high precision capacity for bankruptcy prediction of tourist companies. Also, other previous studies have found that ANN provides a good fit for bankruptcy prediction. In general, for the industry, for example, Callejón et al. (2013), Tsai, Hsu and Yen (2014) and Korol (2013) achieved high precision rates using ANN. And with models focused on the tourism industry, Li and Sun (2012) and Fernández Gámez, Cisneros-Ruiz and Callejón-Gil (2016) managed to improve the precision of existing models for hotels, and Becerra-Vicario et al. (2020) found that ANN outperformed statistical techniques such as Logit in the case of restaurants.

On the other hand, our results have indicated that global models, built from samples of companies with different activities, offer the best fit for predicting bankruptcy in the tourism industry. Although there are no previous global models specially designed for tourism, some studies already pointed to excellent results when considering samples composed of two or more activities. Such is the case of the model proposed by Gu and Gao (2000) with hotels and restaurants, that of Kim and Gu (2006b) for hotels, restaurants, and casinos, and that of Park and Hancer (2012) with a sample of hotels, restaurants and, entertainment service companies. Also, the usefulness and greater precision of global bankruptcy prediction models have already been shown in general in the studies by Alaminos, del Castillo and Fernández (2016) and Laguillo et al. (2019).

Regarding the precision results obtained, we have verified that they surpass those of the previous literature in some cases. For example, Gu's (2002) and Kim and Gu (2006a) models focused 
on restaurants and obtained an accuracy of around $80 \%$. However, compared to other previous studies, our precision results are slightly below those obtained by Young and Gu (2010) and Park and Hancer (2012), which achieved a precision close to $97 \%$ with restaurant samples.

Finally, the most significant variables to explain the bankruptcy situation in the tourism industry, and from the global perspective offered in this study, have been VG2, VG4, VG6, VR2, and VT1. These variables refer to profitability, liabilities coverage, efficiency, leverage, and liquidity. These results partially coincide with those obtained by Pacheco (2015) with Portuguese hotels and restaurants, for which he pointed to leverage as the best predictor of bankruptcy. Also, with those obtained by Fernández, Cisneros and Callejón (2016), Young and $\mathrm{Gu}$ (2010) and Kim and Gu (2006a) regarding the importance of profitability and the ability to liabilities coverage of hotels and restaurants. However, our global model highlights other variables that have not been revealed in previous studies. For example, the efficiency of tourism corporations appeared with a sensitivity greater than $60 \%$ in several of our models and had never been indicted by the literature on bankruptcy prediction in tourism as one of the most impactful. Perhaps, the different definitions of the samples and the study periods used have led to these different results. For example, Young and Gu (2010) included those with negative results for three consecutive years as insolvent hotels, but our study considers as insolvent tourism corporations declared legally bankrupt.

\section{Conclusions and implications}

This study aims to cover the existing gap in the previous literature related to the supposed superiority of global models concerning models focused on predicting bankruptcy in the tourism industry. For this, an empirical investigation has been carried out to overcome the absence of conclusions about the most adequate sample selection for the construction of the models, avoiding the inconclusive results that have been obtained as a consequence of using different methods, databases, periods, and countries. As a result, a database has been made available with information for the 2017-2019 period corresponding to bankrupt and non-bankrupt Spanish companies operating in three important tourism industry sectors (hotels, restaurants, and travel agencies). From the information obtained, global models and focused models have been built applying MLP techniques and a set of variables selected from those that have had the greatest significance in previous studies on bankruptcy prediction.

The results obtained have confirmed the superiority of global models compared to those focused on bankruptcy prediction in the tourism industry. It has been found that the inclusion of sectoral variables increases the predictive capacity of global models, and what is more important, that a global model with said sectoral variables can correctly predict in samples from any of the tourism sectors. Consequently, global models can offer excellent performance to predict the bankruptcy of tourism companies avoiding the high development costs involved in building a model focused on each of the different tourism activities.

These conclusions have important theoretical and practical implications for the literature on the bankruptcy prediction of tourism companies. First, it provides new knowledge about sample selection problems by confirming the superiority of global models over-focused models. These results appear to be a consequence of the current globalisation process, causing a homogenisation of the financial behaviour of companies in the tourism industry. Although there are differences between the significant variables for the models focused on the main tourist activities, these differences are not so significant, and the focused models coincide in many respects. This convergence of bankruptcy predictors finds its maximum expression in the global model, which gathers experience from multiple tourism sectors and can project it with high precision. Second, the empirical evidence obtained also allows us to confirm that ANN techniques provide a great predictive capacity. Specifically, the MLP allows the construction of models for the tourism industry with accuracy greater than $93 \%$. Third, the use of global models can minimise the cost of construction and development of bankruptcy prediction models given the existence of explanatory variables common to the most important activities in the tourism industry. Consequently, tourism companies could manage their bankruptcy prediction models by applying them to all stakeholders with whom they assume financial risks.

Finally, it is also necessary to point out that this study has some limitations, mainly derived from data corresponding to a single geographical area. The results obtained for Spanish tourism companies could be confirmed by reproducing the present study in other tourist contexts and other activities not contemplated here. Also, future research could establish an approach to investigate what macroeconomic conditions affect the behaviour of financial variables that have proven to be good predictors of bankruptcy in the tourism industry.

\section{Acknowledgement}

The researchers would like to acknowledge the Chair of Sustainable Economy and Finance at the University of Malaga, for funding this study through the Tourism, Events, and Cultural Heritage Research Group.

\section{References}

Akaike, H. (1973). Information theory and an extension of the maximum likelihood principle. In Petrov, B. N. and Csaki, F. (Eds.), Second international symposium on information theory, 267-281.

Alaminos, D., del Castillo, A., \& Fernández, M. A. (2016) A Global Model for Bankruptcy Prediction. PLoS ONE, 11(11): e0166693. https://doi.org/10.1371/journal.pone.0166693.

Altman, E. I. (1968). Financial ratios, discriminant analysis and the prediction of corporate bankruptcy. Journal of Finance, 23(4), 589-609. https://doi.org/10.1111/j.1540-6261.1968.tb00843.x.

Amankwah-Amoah, J., Khan, Z., \& Wood, G. (2021). COVID-19 and business failures: The paradoxes of experience, scale, and scope for 
theory and practice. European Management Journal, 39(2), 179-184. https://doi.org/10.1016/j.emj.2020.09.002.

Atiya, A. F. (2001). Bankruptcy Prediction for Credit Risk Using Neural Network: A Survey and New Results. IEEE Transactions on Neural Networks, 12(4), 929-935. https://doi.org/10.1109/72.935101.

Becerra-Vicario, R., Alaminos, D., Aranda, E., \& Fernández-Gámez, M. A. (2020). Deep Recurrent Convolutional Neural Network for Bankruptcy Prediction: A Case of the Restaurant Industry. Sustainability, 12, 5180. https://doi.org/10.3390/su12125180.

Callejón, A. M., Casado, A. M., Fernández, M. A., \& Peláez, J. I. (2013) A System of Insolvency Prediction for industrial companies using a financial alternative model with neural networks. International Journal of Computational Intelligence Systems, 4, 1-13. http://dx.doi.org/10.1080/18756891.2013.754167.

Fernández-Gámez, M. A., Cisneros-Ruiz, A. J., \& Callejón-Gil, A. (2016). Applying a probabilistic neural network to hotel bankruptcy prediction. Tourism \& Management Studies, 12(1), 40-52. https://doi.org/10.18089/tms.2016.12104.

Gu, Z. (2002). Analysing bankruptcy in the restaurant industry: A multiple discriminant model. International Journal of Hospitality Management, 21(1), 25-42. https://doi.org/10.1016/S02784319(01)00013-05.

Gu, Z., \& Gao, L. (2000). A multivariate model for predicting business failures of hospitality firms. Tourism and Hospitality Research, 2(1), 3749. https://doi.org/10.1177/146735840000200108.

Hannan, E. J., \& Quinn, B. G. (1979). The determination of the order of an autoregression. Journal of the Royal Statistical Society, 41, 190-195. https://doi.org/10.1111/j.2517-6161.1979.tb01072.x.

He, H., Zhao, J., \& Sun, G. (2019). The Prediction of Intrinsically Disordered Proteins Based on Feature Selection Algorithms, 12(2), 46. https://doi.org/10.3390/a12020046.

Hedija, V. (2019). Are Bankruptcy Models A Good Predictor Of Firm Financial Distress Of Travel Agents In The Czech Republic? Economy \& Business Journal, 13(1), 87-93.

Higashide, T., Kinkyo, T., \& Hamori, S. (2019). Analysing industry-level vulnerability by predicting financial bankruptcy. Economic Inquiry, 57(4), 2017-2034. https://doi.org/10.1111/ecin.12817.

Jain, A. K., Mao, J., \& Mohiuddin, K. M. (1996). Artificial neural networks: a tutorial. Computer, 29(3), 31-44. https://doi.org/10.1109/2.485891.

Kim, H., \& Gu, Z. (2006a). Predicting Restaurant Bankruptcy. A Logit Model in Comparison with a Discriminant Model. Journal of Hospitality and Tourism Research, 30, 474-493. https://doi.org/10.1177/1096348006290114.

Kim, H., \& Gu, Z. (2006b). A logistic regression analysis for predicting bankruptcy in the Hospitality Industry. The Journal of Hospitality Financial Management, 17-34. https://doi.org/10.1080/10913211.2006.10653812.

Kim, S.Y., \& Upneja, A. (2014). Predicting restaurant financial distress using decision tree and AdaBoosted decisión tree models. Economic Modelling, 36, 354-362. https://doi.org/10.1016/j.econmod.2013.10.005.

Korol, T. (2013). Early warning models against bankruptcy risk for Central European and Latin American enterprises. Economic Modelling, 31, 22-30. http://dx.doi.org/10.1016/j.econmod.2012.11.017.

Laguillo, G., del Castillo, A., Fernández, M. A., \& Becerra, R. (2019). Focused vs unfocused models for bankruptcy prediction: Empirical evidence for Spain. Contaduría y Administración, 64(2), 1-22. http://dx.doi.org/10.22201/fca.24488410e.2018.1488.

Lin, T. H. (2009). A cross model study of corporate financial distress prediction in Taiwan: Multiple discriminant analysis, Logit, probit and neural networks models. Neurocomputing, 72, 3507-3516. http://dx.doi.org/10.1016/j.neucom.2009.02.018.

Li, H., \& Sun, J. (2012). Forecasting business failure: The use of nearestneighbour support vectors and correcting imbalanced samplesEvidence from Chinese hotel industry. Tourism Management, 33, 622634. http://dx.doi.org/10.1016/tourman.2011.07.004.

Nuñez de Castro, L., \& von Zuben, F. J. (1998). Optimised Training Techniques for Feedforward Neural Networks. Technical Report DCA-RT 03/98. Department of Computer Engineering and Industrial Automation. FEE/UNICAMP, Brasil.

Ohlson, J. A. (1980). Financial ratios and the probabilistic Prediction of Bankruptcy. Journal of Accounting Research, 18(1), 109-131. http://dx.doi.org/10.2307/2490395.

Pacheco, L. (2015). SMEs probability of default: the case of hospitality sector. Tourims \& Management Studies, 11(1), 153-159.

Park, S. M., \& Hancer, M. (2012). A comparative study of Logit and artificial neural networks in predicting bankruptcy in the hospitality industry. Tourism Economics, 18(2), 311-338. https://doi.org/10.5367/te.2012.0113.

Schwarz, G. (1978). Estimating the dimension of a model. Annals of Statistics, 6(2), 461-464. http://dx.doi.org/10.1214/aos/1176344136.

Tsai, C., Hsu, Y., \& Yen, D. C. (2014). A comparative study of classifier ensembles for bankruptcy prediction. Applied Soft Computing, 24, 977984. http://dx.doi.org/10.1016/j.asoc.2014.08.047.

Wu, C. H., Tzeng, G. H., Goo, Y. J., \& Fang, W. C. (2007). A real-valued genetic algorithm to optimise the parameters of support vector machine for predicting bankruptcy. Expert System with Applications, 32, 397-408. https://doi.org/10.1016/j.eswa.2005.12.008.

Young, H., \& Gu, Z. (2010). Predicting Korean lodging firm failures: An artificial neural network model along with a logistic regression model. International Journal of Hospitality Management, 29(1), 120-127. http://dx.doi.org/ 10.1016/j.ijhm.2009.06.007.

Zhou, L. (2013). Performance of corporate bankruptcy prediction models on imbalanced dataset: The effect of sampling methods. Knowledge-Based Systems, 41, 16-25. http://dx.doi.org/10.1016/j.knosys.2012.12.007. 